\title{
SUBVERSÕES DO OLHAR: evidências temporais de uma microssociologia dos espaços urbanos ${ }^{1}$
}

\author{
Irlys Alencar Firmo Barreira* \\ Geísa Mattos de Araújo Lima**
}

\begin{abstract}
O presente artigo, com base em teses e dissertações produzidas desde a segunda metade da década de 1990, no Programa de Pós-Graduação em Sociologia da Universidade Federal do Ceará, analisa o percurso teórico-empírico da produção sociológica e antropológica que teve o tema da cidade como objeto de investigação. Os trabalhos analisados expressam movimentos teóricos e metodológicos predominantes nesse período das ciências sociais no Brasil. Demonstram também o crescente interesse pelos recortes microssociológicos nas abordagens sobre o urbano como um dos efeitos da influência da antropologia no tratamento teórico e metodológico dos objetos. Emerge, do conjunto dos trabalhos, a dimensão conflituosa de práticas do poder em relação aos territórios na cidade, influenciados por abordagens vindas da geografia política. A sociologia e a historiografia francesas contribuem com perspectivas teóricas que priorizam os sentidos de criação e insubordinação conferidos aos lugares vividos por distintos atores sociais. No conjunto dos trabalhos, o bairro aparece como microcosmo de práticas sociais permeadas por sentidos de pertença e conflitos de lugares expressivos de lutas sociais mais amplas.

PALAVRAS-CHAVE: Sociologia. Espaços urbanos. Abordagens. Produção discente.
\end{abstract}

Frequentemente excluídas de uma análise sobre a produção do conhecimento no campo sociológico ou antropológico, as teses e dissertações produzidas no conjunto dos programas de pósgraduação funcionam como espécies de ritos corporificados em documentos, importantes para conferirem um diploma, mas pouco afeitos a uma

${ }^{1}$ Uma primeira versão deste trabalho foi apresentada no simpósio 464 "El giro cultural do espaço urbano: reflexões a partir do discurso sociológico", no $54^{\circ}$ Congresso Internacional de Americanistas, em Viena, 2012. Apresentamos, ainda, uma versão modificada na Sessão Temática 06 "Espaço e Território no pensamento brasileiro: história, ciências sociais e questões de pesquisa", no $37^{\circ}$ Encontro Anual da Associação Nacional de PósGraduação e Pesquisa em Ciências Sociais - ANPOCS em Águas de Lindóia, em 2013. O texto aqui publicado buscou incorporar algumas das contribuições dos colegas nos dois eventos. Agradecemos aqui, em especial, às sugestões do comentarista do nosso trabalho na Anpocs, Antônio da Silveira Brasil Jr (UFF), e do coordenador da sessão, João Maia (CPDOC/FVG-RJ).

* Doutora em Sociologia. Professora titular de sociologia do Programa de Pós-graduação em Sociologia da Universidade Federal do Ceará. Pós doutora na École des Hautes Études en Sciences Sociales - EHESS (Paris) e Instituto de Ciências Sociais - ICS (Lisboa). Pesquisadora do CNPq. Av da Universidade, 2995. Benfica. CEP: 60020-181. Fortaleza - Ceará - Brasil. ialencar21@uol.com.br

* * Doutora em Sociologia. Professora do Departamento de Ciências Sociais e do Programa de Pós-Graduação em Sociologia da Universidade Federal do Ceará - UFC. Integra a equipe de pesquisadores do Laboratório de Pesquisas em Política e Cultura - LEPEC. geisamattoslima@gmail.com investigação sobre sua forma de construção e sua expressividade no campo intelectual. ${ }^{2}$

A hipótese desenvolvida no presente artigo é a de que as teses e dissertações, para além de uma função pontual de conferência de títulos, constituem um registro importante de percepção das apropriações teóricas e metodológicas de correntes de pensamento, na área de ciências sociais, feitas por jovens pesquisadores considerados aptos ao ingresso na carreira acadêmica.

A percepção de que as teses e dissertações exprimem modos de produção acadêmica de uma época contém alguns pressupostos. Não só a situação de aluno-aprendiz condiciona a atualização de referências teóricas bibliográficas utilizadas em

2 Alguns trabalhos exemplares empreenderam esforços para elucidar a expressividade do campo das ciências sociais no Brasil levando em conta a produção mais ampla, como o de Manuel Palácios Melo (1999), ou enfocando a influência de um autor específico, como a coletânea organizada por Rubem Barboza Filho e Fernando Perlatto (2012) sobre a obra de Luiz Werneck Viana. Outras referências sobre a cidade e o espaço urbano no Brasil, contemplando levantamento bibliográfico, podem ser encontradas em Eckert, Cornélia "Cidade e política: nas trilhas de uma antropologia da e na cidade no Brasil. (2010) e "Espaço Urbano no Brasil", Frehse, Fraya; Leite, Rogério Proença (2010). 
sua pesquisa, como as percepções de avaliadores, incluindo orientadores, consideram relevante a comprovação do domínio sobre o estado da arte em suas diferentes especializações. As citações, as referências teóricas e a atualização bibliográfica constituem espécies de quesitos obrigatórios que legitimam os trabalhos de tese e dissertação, mesmos aqueles caracterizados por introduzir aspectos originais oriundos de suas pesquisas.

Tomar esse material como peça reveladora de movimentos teóricos, abordagens e perspectivas de investigação, nas áreas de sociologia e antropologia, signatários de momentos específicos da construção do conhecimento, pareceu-nos um caminho interessante para pensar sobre a dinâmica reflexiva das ciências sociais. A hipótese aqui desenvolvida é a de que as teses e dissertações expressam - na escolha de temas, no uso de autores e nos modos de realizar a pesquisa - momentos especiais de construir e reproduzir conhecimentos em campos específicos da prática acadêmica.

Tomamos como recorte para esta reflexão as teses e dissertações do Programa de Pós-Graduação em Sociologia (PPGS) da Universidade Federal do Ceará (UFC) defendidas no intervalo de 1990 a 2010 que elegeram o espaço urbano de Fortaleza como referencial teórico e empírico de pesquisa. Trata-se de trabalhos que expressam diferentes formas de articulação entre dados de pesquisa e aportes analíticos, o que permite observar, no intervalo de mais de duas décadas, mudanças de enfoque e modos variados de apropriação do tema.

Em termos gerais, os recortes de objeto aqui apresentados são parte de uma dinâmica global que não se restringe ao PPGS da UFC e, embora expresse uma forma delimitada de análise, apresenta tendências gerais da investigação sociológica que podem ser observadas, em maior ou menor escala, em outros lugares de exercício da produção acadêmica. ${ }^{3}$ Buscamos captar uma dinâmica certamente ca-

${ }^{3}$ No livro Da periferia ao centro: trajetórias de pesquisa em Antropologia Urbana (2012), José Guilherme Cantor Magnani, coordenador do Núcleo de Antropologia Urbana da Universidade de São Paulo (NAU-USP) desde 1988, recupera a linhagem de autores, enfoques teóricometodológicos, bem como os contextos políticos, sociais e acadêmicos que conduziram ao desenvolvimento racterizada por expressões semelhantes vigentes em outros contextos acadêmicos, tendo em vista as influências advindas das trocas acadêmicas realizadas nos espaços dos congressos, das pós-graduações e das bancas examinadoras. Vale ressaltar que, hoje, as ciências sociais caracterizam-se por grande mobilidade na difusão do conhecimento explicitada em eventos e acessibilidade por meio da internet, retirando, assim, parte significativa do que poderia ser identificado como "especificidade regional”.

Nesse sentido, não chega a ser surpreendente a recorrência, em teses e dissertações, a autores e teorias, acompanhados de recortes metodológicos temporalmente convergentes, funcionando como espécies de "moda” e apresentando caminhos certamente impensáveis ou inusitados em outros momentos da produção do conhecimento.

O presente artigo representa um extrato da pesquisa registrada no departamento de Ciências Sociais da Universidade Federal do Ceará ${ }^{4}$ com o título "Fortaleza: percepção de uma cidade no discurso acadêmico". A constatação da existência de um volume significativo de teses e dissertações nas quais a cidade aparece, de forma explícita ou indireta, como objeto de investigação, percorrendo distintos períodos no PPGS da UFC, suscitou as primeiras indagações sobre o caráter significativo daquela produção e sua capacidade de apontar tendências teóricas, registros peculiares ao contexto local, enfim, modos diferenciados de realizar o saber sociológico e antropológico.

Nosso objetivo é explorar um dos itens que compõem o escopo temático das teses e dissertações do PPGS, que poderia ser classificado pela designação de "estudos urbanos". As variações desse enquadramento temático, seja no uso e apropriação do pensamento de autores, seja nas formas de pesquisa ou nas perspectivas que com-

da Antropologia Urbana na USP. O autor nos concedeu entrevista durante a ANPOCS, em outubro de 2012, na qual discutiu os resultados da pesquisa, contribuindo, assim, para refletir de forma comparada sobre as experiências dos estudos urbanos na USP e na UFC. Trechos dessa entrevista serão citados adiante.

${ }^{4}$ O Programa de Pós-Graduação em Sociologia da UFC iniciou o curso de mestrado em 1976, sendo o doutorado criado em 1993. Até o momento, foram defendidas 581 dissertações e teses. 
põem o "recorte do objeto", constituem a diretriz que informará os argumentos desenvolvidos ao longo do texto. Assim, o tema "urbano", enfocando a cidade em diferentes perspectivas, constitui uma porta de entrada interessante para se verificar a presença de convergências temáticas que aparecem no tratamento teórico e empírico do objeto.

Foram selecionados inicialmente, na triagem de pesquisa, 30 trabalhos (incluindo teses e dissertações) que foram lidos, resumidos e discutidos por uma equipe voluntária de estudantes de Graduação e Pós-Graduação em Ciências Sociais, ${ }^{5}$ ficando posteriormente restritos a 27. ${ }^{6}$ Para uma seleção mais pontual foi levado em conta o caráter explícito que a cidade assumia como tema de pesquisa e reflexão, considerando que uma perspectiva muito alargada, que abrangesse todas as investigações feitas na cidade, poderia perder de vista as peculiaridades do recorte baseado em uma percepção sobre o fenômeno urbano ${ }^{7}$ em sua especificidade. Entendemos, como Magnani (2002, p.25), que o campo de estudos pode ser delimitado

[...] reservando a denominação de antropologia urbana stricto sensu para o estudo dos grupos sociais e suas práticas quando propriamente ins-

${ }^{5}$ Ao longo do projeto, foram realizadas quatro reuniões de apresentação das sínteses feitas pelos voluntários e de discussão das categorias centrais identificadas por eles nas leituras. Participaram desta pesquisa os seguintes estudantes de Graduação em Ciências Sociais, UFC: João Miguel de Araújo Lima, Luan Teixeira, Sérgio Martins (bolsistas do CNPq), Caio Feitosa, Bruno Duarte, Ana Rafaela Sousa, Daniel de Castro, Márlia Paiva, Eliakim Lucena, Josileine Abreu, Deisiane Aguiar (voluntários). Participaram ainda os estudantes de Pós-Graduação em Sociologia: Juliana Avelar, Ercílio Langa e Marília Passos (Mestrado) e Igor Monteiro (Doutorado). Participou ainda o doutorando em Antropologia pela Universidade Paris 3, Nova Sorbonne, Centro de Altos Estudos sobre América Latina, Julien Zeppetella.

${ }^{6}$ Os trabalhos selecionados estão citados de modo completo nas referências. Em ordem cronológica, os autores são: Arrais (1993); Vale (1997); Barbosa (1997); Diógenes (1998); Pimentel (1998); Bezerra (1999); Schramm (2001); Aragão (2002); Freitas (2003); Prado (2003); Moreira (2004); Mattos (2004); Lima Filho (2004); Pimentel (2004); Oliveira (2006); Maciel (2006); Albuquerque (2006); Gadelha (2007); Paiva (2007); Matos Jr. (2008); Bezerra (2008); Monteiro (2008); Vasconcelos (2008); Mesquita (2009); Viana (2009); Ribeiro (2010) e Sá (2010).

${ }^{7}$ A preocupação em distinguir, de forma mais restrita, o campo da antropologia urbana está presente em obra clássica de Ulf Hannerz (1983), que analisa a produção sobre cidade na sociologia e antropologia, principalmente nos Estados Unidos e na Europa. Também vem sendo tratada por Heitor Frugóli Jr (2005) e por Magnani (2002), de modos diferentes, no contexto da antropologia urbana nacional. critos na trama da cidade, isto é, articulados na e com a paisagem, equipamentos ou instituições urbanas, considerados não como mero cenário, mas como parte constitutiva dessas práticas. Trata-se de uma primeira aproximação à complexidade da dinâmica urbana contemporânea: nesse plano, a unidade de análise da antropologia urbana seria constituída pelas diferentes práticas e não pela cidade como uma totalidade ou uma forma específica de assentamento, configurando o que se entende antes por antropologia na cidade e não - ao menos não ainda - como antropologia $d a$ cidade. $^{8}$

Os trabalhos que foram então identificados como relevantes para a pesquisa refletem sobre práticas sociais articuladas de forma intrínseca e direta à realidade urbana. A amostra analisada foi representativa, embora não ampliada, considerando-se a rede de interações temáticas presente nos trabalhos observados sob a óptica da cidade. Certamente uma leitura mais pormenorizada de outros trabalhos produzidos no mesmo período que compreende o início dos anos 1990 até 2010poderia levar a mais “achados” em pesquisas que não tratavam diretamente da cidade, mas a tinham como lócus de referência. Identificamos, portanto, uma separação entre investigações feitas na cidade e investigações feitas sobre a cidade, sendo essa última classificação a escolhida como tema fundamental da análise sobre a produção do conhecimento das teses e dissertações.

Os estudantes de Graduação e Pós-Graduação em Sociologia que participaram da pesquisa foram treinados para as leituras de forma a registrar: o objeto de cada tese e dissertação analisada; as principais abordagens teórico-metodológicas; as categorias analíticas e categorias "nativas" centrais; os autores mais citados e os "parágrafos-chave", isto é, os mais significativos e diretamente alusivos ao conteúdo de cada texto. Reuniões de trabalho e checagem das informações coletadas em fichas permitiram o afinamento de instrumentos e a convergência de critérios de identificação. Essa perspectiva foi fundamental para balizar instru-

${ }^{8} \mathrm{O}$ autor, no entanto, no mesmo texto, demonstra que seu objetivo final é o de seguir em busca de princípios mais abrangentes, de estruturas de longa duração e da referência a planos e modelos mais amplos, na direção, aí sim, de uma antropologia da cidade (Magnani, 2002, p. 26). 
mentos comuns e identificar, nos trabalhos, as convergências, movimentos e mudanças no decorrer do tempo.

Os trabalhos escolhidos e analisados tiveram como referência a apresentação indicativa de categorias analíticas das formas de olhar a cidade. As recorrências encontradas certamente refletiam os novos paradigmas oriundos das leituras mais em voga e das discussões em sala de aula no PPGS e nos congressos de ciências sociais do período. A amostra analisada foi também reveladora da importância que a reflexão específica sobre o fenômeno urbano obteve nos últimos 15 anos entre os cientistas sociais no Brasil.

\section{A CIDADE COMO PONTO DE REFERÊNCIA}

Uma mudança de enfoque sobre a cidade, antes pensada como unidade, para uma abordagem centrada em delimitações que poderiam ser designadas como microssociais demarca um novo momento da produção das teses e dissertações. As "marcas locais da cidade" aparecem na escolha de bairros e espaços dotados de usos específicos (aeroporto, praias, praças e cinemas), apontando a dinamicidade e variabilidade do fluxo urbano.

Defato, observando-se as marcas hegemônicas da sociologia urbana presentes, por exemplo, nos trabalhos de Castells (1980), Topalov (1979), Préteceille (1985), Kowarick (1983) e outros, verifica-se que a abordagem que enfocava a cidade como expressão de conflitos ou contradições estruturais modelava anteriormente parte significativa das produções na área. A metrópole e seus conflitos, a gestão dos meios de consumo urbanos e as desigualdades de acesso aos espaços citadinos constituíam as referências analíticas mais presentes, veiculadas, sobretudo, desde o final da década de 1970 e meados dos anos 1980.

Sob o enquadramento do tema "movimentos sociais", sobretudo no final da década de 1980 e início dos anos 1990, as dissertações e teses apresentaram um recorte sobre os bairros como protagonistas de demandas e práticas de contestação.
Expressivos de uma condição de exclusão de bens coletivos de consumo, os bairros populares, nomeados muitas vezes de "periféricos", eram percebidos menos como um lugar dotado de sociabilidades peculiares e mais como exemplo de carências sociais e demandas mobilizadas por atores coletivos. A falta de acesso aos bens de consumo foi vista como expressão da cidade fragmentada pela desigualdade social, marcada menos pela diversidade de usos do espaço. Essa forma de abordagem alimentou-se também nos trabalhos voltados para o entendimento da política em espaços cotidianos da vida urbana.

Se essa perspectiva de abordagem segue as tendências das principais universidades brasileiras, no PPGS/UFC, até o final dos anos 1980, na década seguinte, os movimentos sociais nos bairros de periferia recebem um tratamento mais próximo das etnografias, atento aos significados e suas transformações, em abordagens interessadas nos processos culturais. Nesses trabalhos, são frequentes as perspectivas das relações dos moradores da periferia com o Estado e das políticas públicas voltadas para eles (Andrade, 1991), bem como sobre os processos de construção de "lideranças comunitárias” (Sousa, 1997). Também se incluem, nesse recorte, trabalhos voltados para a análise da atuação da Igreja Católica (Miranda, 1985; Cordeiro, 1989), e no campo da sociologia da comunicação (Nunes, 1991; Oliveira, 1994).

No espaço acadêmico da produção de trabalhos, convém levar em conta a influência de orientadores e as orientações teóricas de cursos que exerceram papel importante na delimitação de abordagens. ${ }^{9}$ Assim, trabalhos sobre movimentos sociais tiveram a influência da linha de pesquisa

Ao recuperar linhagens e trajetórias que conduzem ao desenvolvimento da Antropologia Urbana na USP (2012), Magnani concede destaque ao papel de orientação de Ruth Cardoso e Eunice Durham, e apresenta uma lista de dissertações e teses de mestrado e doutorado que demonstram os novos recortes de pesquisa surgidos entre 1977 e 1987, sob a influência dessas professoras. O autor nota, a despeito do aparente ecletismo dos temas de pesquisa, que se sobressaem os temas: trabalho, família, religião, periferia urbana e classes populares, educação, famílias de classe média, trabalho feminino. "Num total de 25 orientações (quinze teses e dez dissertações), é possível constatar a presença da cidade como espaço ou contexto do recorte escolhido" (Magnani, 2012, p.60). 
denominada “Cultura e Política”, que agregou parte significativa das dissertações e teses em confluência com a linha de pesquisa designada "Cidade, Movimentos Sociais e Práticas Culturais". O fato de o Programa de Pós-graduação manter estreita conexão entre as áreas de sociologia e antropologia também interferiu na construção de interfaces entre estudos culturais e políticos presentes na cidade.

É possível afirmar que, partir do final dos anos 1990, as pesquisas sofrem uma espécie de inflexão. Os trabalhos que tomam a cidade como objeto de investigação no Programa de Pós-Graduação em Sociologia da UFC passam a incorporar os conceitos de território e de espaço seguindo, entre outros, o arcabouço conceitual de Félix Guatarri e Michel de Certeau. O artigo de Guattari (1985) denominado "Espaço e poder: a criação de territórios na cidade" passa a ser uma das referências importantes nos estudos sobre cidade no Brasil, e não só para a sociologia e antropologia, mas também para a arquitetura e a geografia. Já no começo dos anos 2000, foi a série de cinco volumes de Mil Platôs, lançada com Deleuze (1995), que veio a exercer influência nas pesquisas de mestrado e doutorado, introduzindo outra perspectiva analítica sobre o espaço urbano e contribuindo para a passagem de uma sociologia ou antropologia na cidade, para uma antropologia ou sociologia $d a$ cidade vista como múltipla e complexa em seus usos e significados.

Tomando por base a perspectiva da "micropolítica do cotidiano", introduzida por Michel Foucault (1979), Deleuze e Guattari incorporam não só o exame das relações de poder, mas a produção de subjetividades tendo em vista ampliar a percepção sobre a criação de territórios na cidade. O território estaria ligado a uma "ordem de subjetivação individual e coletiva”, firmando-se como espaço de "relações funcionais de toda ordem". Se o espaço atuaria como uma referência extrínseca em relação aos objetos que ele contém, o território estaria em uma relação intrínseca com a subjetividade que o delimita. O conceito de território, mais que um referente geográfico, constitui, no âmbito dos trabalhos analisados, o componen- te simbólico de registro de um "lugar" social, podendo representar zonas de recomposição e de identificação entre os indivíduos e os espaços vividos (Guattari; Rolnik, 1986).

Essa perspectiva aparece em uma das primeiras teses do PPGS-UFC (Diógenes, 1998, p. 204205), que pensava localmente a importância da construção simbólica de territórios, no caso específico, a partir das disputas entre os integrantes de gangues, que

[...] criam uma trama de domínio territorial, mobilizam enfrentamentos nesses campos de ação, canalizam energias vigilantes e violentas para a demarcação de fronteiras e, nessa coreografia de um poder sobre o espaço, estrategizam a visualização e a demarcação do território corpo.

Outro exemplo de dissertação (Vale, 1997, 2000) elaborada no mesmo período, também buscou inspiração na ideia de território como construção simbólica, sem subsumi-lo à noção de identidade, considerada pelo autor pouco adequada para pensar a complexidade das relações que são estabelecidas com o público frequentador do Cine Jangada. ${ }^{10} \mathrm{O}$ trabalho de Vale (2000, p.14) pode ser considerado marcante para uma antropologia $d a$ cidade no Programa de Pós-Graduação em Sociologia da UFC, uma vez que ele se dispôs a "[...] contribuir para desenhar um novo tipo de mapa, com o qual se pudesse descrever e compreender a metrópole, suas modalidades de diversão, seus funcionamentos marginais". Os modos de utilização do espaço como produção de subjetividades é construído tendo em vista captar os "esquemas mentais" e "corporais" de frequentadores que operavam no interior da sala de exibição, incluindo "[...] as distintas motivações que os levavam àquela sala, bem como os encontros e conflitos que ali ocorriam, enfatizando a atuação dos travestis e o mercado da prostituição no Cine Jangada” (Vale, 2000, p. 15).

Nota-se também, nesses primeiros trabalhos nos quais a cidade é tematizada como objeto, a

${ }^{10}$ Cine situado no centro de Fortaleza, que existiu durante 47 anos e tornou-se, na década de 1990, local de exibição de filme do gênero pornô destinado ao público de gays e travestis. 
influência de Michel Foucault, com a atenção dirigida para os movimentos dos corpos no espaço, buscando dar conta de variadas expressões do exercício do poder, percebido por meio de práticas sociais, lutas e posições estratégicas, e não se apresentando como substância definida por uma posse ou lugar. A abordagem foucaultiana contribui para a percepção do poder sob o signo da positividade que produz com o corpo, e não só o recalca ou disciplina.

Nos trabalhos citados anteriormente, o espaço é apropriado pelos "corpos em movimento", refletindo tensões e conflitos da sociedade mais ampla. Descreve-se, por exemplo, os movimentos das gangues pela cidade como tensões permanentes entre a aventura da expansão, da conquista de outros espaços, e a concentração em “áreas” específicas, isto é, lugares onde se sentem a salvo de rivais e da polícia.

As interações sociais em uma sala de cinema pornô são percebidas como sendo, sobretudo, corporais, conferindo às palavras um papel secundário. Nas experiências de transgressão vividas pelos corpos na plateia, é estabelecida uma cumplicidade na pertença a um "território marginal". Assim, busca-se "[...] trazer à tona 'mapas urbanos invisíveis' e territorialidades da cidade que remetem a questões como marginalização e estigmatização sociais" (Vale, 2000, p. 22).

\section{ANTROPOLOGIA E GEOGRAFIA}

A ênfase na cultura como eixo de compreensão sociológica tornava-se um paradigma na década de 1990 nas pós-graduações em sociologia. Barreira (1997, p. 35) assinala que os grupos de trabalhos apresentados à ANPOCS a partir de 1994 passaram a ter o tema da cultura como complemento - "Cultura e Mídia”, "Cultura e Identidade", "Cultura e Etnia" -, o que a autora identifica como "[...] busca de explicações que remetem ao tema da cultura, atuando como variável mediadora entre processos e comportamentos sociais".

Na esteira dessa (re) valorização da cultura e da antropologia, aparece uma série de trabalhos no PPGS com abordagens diversificadas da vida social. Os lugares da cidade a serem abordados deixam de ser predominantemente ligados ao mundo do trabalho, como nos anos 1970, ou da exclusão dos bens de consumo coletivo, nos anos 1980, para se dirigirem aos locais de culto religioso, aos palcos, aos presídios, às praias, aos bares. A cidade passa a ser abordada em recortes cada vez mais microssociológicos, como nas dissertações sobre praças, aeroportos ou sobre partes de um bairro, tomados como lugares significativos.

A influência da antropologia de modo mais generalizado em quase todos os trabalhos analisados chega, principalmente, a partir de Clifford Geertz (1989) nos anos 1990. Parte significativa dos autores, a partir desse período, cita o conceito de cultura e de etnografia do autor em A Interpretação das Culturas. E muitos pretendem fazer etnografia como "descrição densa", tomando a cidade como ponto de referência.

Outra vertente baseada na antropologia da política tomou a dimensão de espaços urbanos, notadamente os bairros de outra perspectiva, recuperando a voz de atores e as formas da linguagem nativa como parte importante dos acontecimentos sociais. ${ }^{11}$ Uma tese que tem por tema a disputa entre candidatos a vereador em um bairro da periferia (Mattos, 2004) demonstra a influência marcante da "antropologia da política", que valoriza os "processos" e "interações sociais concretas", ao invés de "sistemas" e "funções" (Goldman; Palmeira, 1996, p. 2-3). ${ }^{12}$ Assim, diferentes enfoques sobre um mesmo lugar aparecem relativos e situados, dependendo de quem fala e de onde se fala. Trata-se não só de uma questão de relativização das posições sobre o lugar. É o próprio espaço que é

${ }^{11}$ O Núcleo de Antropologia da Política (NUAP), fundado em 1977 e sediado no Programa de Pós-graduação em Antropologia Social do Museu Nacional, incorporou pesquisadores da Universidade Federal do Ceará articulados em torno do projeto "Uma antropologia da política: rituais, representações e violência com suporte do Programa de Apoio a Núcleos de Excelência (PRONEX).

${ }^{12}$ Os autores fazem a história desse movimento, que vem desde a antropologia política britânica nos anos 1960 . Ver a apresentação do livro Antropologia, Voto e Representação Política, organizado por eles (Goldman; Palmeira, 1996). 
tematizado a partir das relações de poder, concebidas como parte das interações sociais mais amplas que, inclusive, ultrapassam a condição de lugar. ${ }^{13}$

Outras teses mais recentes são marcadas pela influência da geografia política, sendo os territórios da cidade pensados, a partir de sua dimensão conflituosa, como “[...] campo de forças, uma teia ou rede de relações sociais que, a par de sua complexidade interna, define, ao mesmo tempo, um limite, uma alteridade; a diferença entre nós e os outros" (Souza, 2000).

Exemplo de tese em que se encontra a influência da noção de território oriunda da geografia política tem por objeto o aeroporto de Fortaleza (Mesquita, 2009). Os geógrafos Rogério Haesbaert e Ester Limonard (2007, p. 42-43) definem algumas premissas para pensar as categorias território e espaço: 1) distinguem-nas em favor da maior abrangência dessa última; 2) pensam o território como construção histórica e social a partir das relações de poder; 3) enfocam a dimensão subjetiva, que propõem denominar de "consciência, apropriação ou mesmo, em alguns casos, identidade territorial”, ao lado de uma dimensão mais objetiva, que pode ser denominada "dominação do espaço, num sentido mais concreto, realizada por instrumentos de ação político-administrativa”. É importante ressaltar que a perspectiva de território, que reconhece a presença de alguns aspectos considerados "objetivos" na relação entre poder e espaço, parece ser buscada quando o pesquisador se depara com tipos de situações ou lugares da cidade nos quais a vigência de certos controles político-administrativos parece mais evidente. Éo caso do aeroporto, tomado como objeto de pesquisa como "espaço de fluxos", capaz de produzir “... as estratégias e procedimentos estabelecidos e executados pelas instituições de controle e organização desse espaço e os processos criativos proveni-

${ }^{13}$ Um dos autores muito citados no trabalho de Mattos (2004) é Bailey (1971), antropólogo inglês, considerado um dos expoentes da Escola de Manchester. Bailey, que publicou suas pesquisas principalmente entre 1960 e 1970, é influenciado por Erving Goffman e se dedicou a compreender as regras implícitas do jogo social, consideradas parte intrínseca dos jogos ditos políticos. entes das práticas de tempo e espaço dos demais usuários" (Mesquita, 2009, p. 6).

A investigação não se detém a pensar o aeroporto segundo a classificação de "não lugar", atribuída àquele espaço, como o faz a categorização de Marc Augé (1994), que nega a relação de pertença e de identidade com os que por ali trafegam, a exemplo do que aconteceria também em muitos espaços nas cidades contemporâneas, como shoppings, estações ferroviárias, grandes cadeias de hotéis. Aliando a observação participante à aplicação de questionários, a dissertação buscou compreender como passageiros, acompanhantes, funcionários e comerciários realizam e dão sentido a "práticas de tempo e de espaço", considerando que os "processos de 'territorialização’ no âmbito do aeroporto resultam em relações marcadas pela pressa e pela espera, sem, contudo, inviabilizar sentimentos de pertença." (Mesquita, 2009, p. 6).

A tese sobre a atuação de torcidas organizadas do time de futebol Ceará (Ribeiro, 2010) utilizou como referência um conceito de território advindo da geografia política, que favoreceu a reflexão sobre a ideia de "controle" sobre o espaço. Essa noção tornou-se significativa no campo de pesquisa, já que os territórios foram objeto por excelência de disputas entre as torcidas. A tese abordou o fenômeno a partir do conceito de território do geógrafo Paulo César Gomes, na obra $A$ Condição Urbana (2002). O autor concedeu muita ênfase à ideia de controle sobre o território, pela qual se tornou possível pensar "[...] a imposição de regras de acesso, de circulação e normatização de usos, de atitudes e de comportamentos sobre este espaço [...] é a expressão de um poder, ou seja, ele é aquilo que está em jogo em grande parte das disputas sociais, aí incluídas aquelas que disputam um direito à cidade." (Gomes, 2002, p. 12).

A ideia de território permitiu, nas pesquisas, uma reflexão sobre a espacialidade das relações sociais, observando-se a condensação de práticas e suas especificidades correlatas. Viabilizou também uma compreensão da variabilidade e dinamicidade dos espaços para além do sentido de reprodução e fixação de práticas sociais. É nes- 
sa perspectiva que emergiu a observação de contravenções no uso dos espaços.

\section{CONTRAVENÇÃO DE PRÁTICAS E MUDANÇA NOFOCO DO OLHAR}

Na maioria das teses e dissertações analisadas, observou-se que os autores buscaram enfatizar as práticas de contravenção de usos dos espaços em relação às imposições oficiais e administrativas. Tentaram, não obstante as diferenças de objetos empíricos, compreender como os sujeitos escapavam das ingerências políticas, incluindo o controle sobre a dimensão do tempo e do corpo. Pode-se dizer que as teses e dissertações, não obstante suas diferenças, registraram uma mudança no foco do olhar sobre os espaços da cidade, fugindo tanto ao senso comum como às teorias que enfatizam o peso das instituições e papéis sociais em detrimento da observação da dinâmica dos comportamentos individuais e coletivos.

Na perspectiva de observação de usos alternativos dos espaços, a estratégia metodológica adotada na pesquisa foi a observação e o registro no diário de campo, mesmo que muitos autores não tenham explicitado o uso de etnografias em sentido estrito segundo a percepção antropológica.

A ideia de contravenção, portanto, esteve presente não só na interpretação feita pelos sujeitos pesquisados a respeito de suas práticas, mas também na análise que os autores fizeram sobre os sentidos conferidos aos usos dos espaços urbanos. É possível dizer que os trabalhos de pesquisa presentes nas teses e dissertações buscam (re) construir a cidade, para além das versões previamente estabelecidas, seja do ponto de vista do senso comum, seja das análises prévias baseadas em modelos teóricos generalizantes. A prioridade conferida aos "processos de subjetivação", "territorialização" e "desterritorialização" substitui a abordagem na qual a cidade era preponderantemente analisada por meio da abordagem estrutural segundo as formas capitalistas de dominação. Embora essa abordagem não deixe de estar presente como referente analítico, o que se observa é a existência de um leque bem mais amplo de olhares capazes de registrar sentidos difusos de dominação e insubordinação.

Uma das principais referências analíticas que vem a alimentar esse amplo significado de modificação de enfoque nos trabalhos analisados encontra-se nas categorias utilizadas por Michel de Certeau (1998), as quais vem se somar às contribuições de Deleuze e Guattari, já mencionadas anteriormente, dando suporte aos "processos de subjetivação" que são percebidos como capazes de imprimir marcas específicas na forma de viver a cidade. ${ }^{14}$

Ao procurar pensar a "antidisciplina", Certeau instiga (Certeau, 1998, p. 41): “[...] mais urgente ainda é descobrir como uma sociedade inteira não se reduz a ela: que procedimentos populares (também minúsculos e cotidianos) jogam com os mecanismos da disciplina e não se conformam com ela, a não ser para alterá-los”. Certamente, uma maior autonomia ou liberdade concedida aos atores sociais tem forte inspiração nas formulações de Certeau, fazendo emergir espaços e práticas cotidianas antes subsumidas ou pouco visíveis na ideia da cidade sob o imperativo genérico das disposições econômicas e políticas. O conceito de "uso" permitiu a evidência de atores, locais e práticas diversas. Os usos, em sua diversidade concreta, estavam referidos às formas peculiares de apropriação e ressignificação de práticas sociais.

Os usos que os pescadores fazem da Lagoa, no bairro da Parangaba, por exemplo, foi tema de uma dissertação (Monteiro Jr., 2009) que enfatizou a ideia de inversão de práticas sociais implicada nessa forma de utilização do local. No trabalho de pesquisa, houve a apropriação da categoria denominada ação tática, de Michel de Certeau (1998, p. 47), pela qual o "fraco" vence momentaneamente o "mais forte" utilizando-se de astúcias articuladas para "captar no voo", e obter prazeres ao jogar com as oportunidades do cotidiano. A ênfase na capacidade de o sujeito elaborar modos especiais

${ }^{4}$ Ao contrário de Deleuze e Guatarri, mais tributários da herança de Foucault, Certeau critica a abordagem foucaultiana que, segundo ele, "privilegia o aparelho produtor da disciplina”. 
de consumir o espaço terminou permitindo enfatizar processos criativos para além do suposto imperativo disciplinar. Na versão do autor (2009, p. 92), os pescadores "[...] ao se apropriarem da lagoa, subvertem tal distinção, reforçando o caráter social e ativo na construção dos espaços sociais que constituem o terreno das sociabilidades e das subversões".

Chama a atenção também, no contexto dessa mudança de interpretação dos significados relacionados aos espaços urbanos, uma relativização da distinção entre "cidade" e "natureza". A relação intrínseca entre esses dois polos, colocados, muitas vezes, como opostos, ${ }^{15}$ torna-se relevante para se perceber como os sujeitos elaboram suas "táticas" ou "linhas de fuga" (para usar, respectivamente, as expressões de Certeau e de Deleuze, dois autores muito influentes nos trabalhos aqui analisados), sendo o ambiente natural o grande "tesouro escondido" na cidade invisível. "Cidade" e "natureza" constituem duas faces da mesma moeda na elaboração dos sentidos dados aos lugares, pois não se pode compreender a relação dos moradores com a cidade sem passar pelos usos e apropriações dos sujeitos sobre o mar, a praia, o mangue, as lagoas, as árvores, as várias espécies de animais, ainda que só sejam visíveis para alguns.

Outros trabalhos de pesquisa enfatizam a apropriação criativa de espaços por atores sociais. Em dissertação sobre a prática do surf nas praias da Leste-Oeste e do Icaraí (Albuquerque, 2007, p. 160 ), a autora destaca que os usos feitos do mar por moradores de bairros da "periferia praiana" dão a eles sensação de pertença e domínio sobre o espaço, criando um sentimento intenso de 'posse' que os indivíduos estabelecem com o território onde ocupam, ou seja, com o pico onde "tradicionalmente' praticam o surfe."

${ }^{15}$ Em pesquisa sobre os pescadores na Lagoa de Parangaba, Hélio Monteiro Júnior (2009, p. 23-24) é levado a questionar a dicotomia entre "rural" e "urbano", utilizada nos trabalhos da chamada Escola de Chicago. Analisando esse fenômeno urbano, o autor percebe uma fusão com aspectos culturais que seriam tidos como tipicamente rurais, expressando a multiplicidade que caracteriza os modos de vida nas cidades contemporâneas.
Na mesma direção de inversão dos olhares sobre a cidade, destaca-se a tese sobre os jovens do Serviluz, também "periferia praiana", elaborada a partir da convivência do pesquisador com surfistas e moradores de ruas próximas à praia do Titanzinho. Naquele bairro, “[...] a violência, o medo e o risco fazem da experiência dos jovens do Titanzinho uma aventura desde a infância até a idade adulta." (Sá, 2010, p. 239-240). A construção de uma positividade para as identidades de moradores de bairros tidos como "favelas perigosas" passa pela "[...] afirmação de valores e pertencimentos alternativos, não hegemônicos, em confronto com a produção social da indiferença, na ordem social excludente da cidade de Fortaleza que desclassifica os moradores do Serviluz há 70 anos." (Sá, 2010).

Outra compreensão de "cidade invisível" que uma inversão do olhar possibilitou revelar está na dissertação sobre memórias de trabalhadores do lixo em Fortaleza (Aragão, 2002). Nesse caso, a mudança de análise se dá tanto pela escolha do objeto de pesquisa, quanto pelas leituras surpreendentes, para o senso comum, que seus interlocutores - os trabalhadores do lixo - fazem da cidade, através de suas lembranças. "Remexendo suas memórias, olho a cidade vista e delineada por eles" (2002, p. 14-15). O que se encontra vai muito além da afirmação já conhecida da ideia de uma cidade desigual e injusta, embora estes aspectos também estejam presentes nas narrativas dos sujeitos pesquisados.

Embora a análise remeta aos depoimentos de trabalhadores cujas memórias sobre o trabalho são marcadas pelo ressentimento, há também o encontro com uma antiga catadora de lixo que interpreta o seu tempo de vida e trabalho no lixo como uma forma de insubordinação ao sistema. $\mathrm{O}$ lixão é visto como um lugar de lazer e diversão: "Tenho saudade daquele tempo! Tenho. Só pra fazer bonecage [...] Porque ali dentro da usina não tem home. Só tem fulerage." Complementa afirmando: "[...] pra mim aqui não teve dificuldade nenhuma [...]” (Aragão, 2002, p. 129-130). 


\section{UMA SOCIOANTROPOLOGIA DOS BAIRROS}

O estudo sobre a sociabilidade dos jovens no bairro Serviluz, objeto de pesquisa na tese citada anteriormente, faz parte de um conjunto de outros trabalhos que também elegeram, como campos de pesquisa, locais de moradia tidos como "perigosos" nos discursos midiáticos. É o caso de Aerolândia (Matos Jr., 2008), Bom Jardim (Paiva, 2007), Conjunto Palmeiras (Mattos, 2004), e Pirambu (Prado, 2003), bairros situados na chamada zona periférica da cidade.

É importante ressaltar que as teses e dissertações tomadas como objeto de investigação não tinham como objetivo prioritariamente pensar a relação entre bairro e cidade, uma vez que seus focos de interesse eram, nos três primeiros casos, diferentes formas de viver a violência, e, nos dois últimos, de viver a política e o cotidiano. No entanto, ao longo do trabalho de campo, o bairro apareceu como uma categoria definidora abrangente para pensar sobre uma variedade de temas circunscritos a um microcosmo portador de dinâmicas sociais complexas.

Na perspectiva de pensar sobre essa elaboração metonímica, é possível propor a seguinte questão: Quais as consequências advindas das formas mais recentes de pensar a cidade a partir dos bairros? Percebendo essa problemática do ponto de vista "nativo", a lógica de pertencimento pode estar referenciada nessa territorialidade denominada como "bairro"? Em outras palavras, como apropriar-se do "bairro" em um contexto de grande complexidade, tal como a vida nas grandes cidades contemporâneas, nas quais as redes de relações sociais ultrapassam em muito os mecanismos tradicionais de identificação, como a vizinhança ou o lugar de moradia?

Instigado a refletir sobre essas questões, em entrevista concedida especialmente para esta pesquisa em 2012, o antropólogo José Guilherme Magnani, um dos autores brasileiros bastante referidos nas teses e dissertações do PPGS da UFC, reconheceu a complexidade de se tomar o bairro como referência sem reificá-lo:
Do ponto de vista da pesquisa das ciências humanas, não se pode partir do princípio de que [o bairro] constitui uma unidade, porque ele tem uma heterogeneidade cultural, uma diversidade na sociabilidade muito grande. [...] Então a solução é o que eu chamo a construção da unidade de sentido. A unidade da inteligibilidade. [...] Em alguns momentos o bairro pode ser uma totalidade, em outros não. ${ }^{16}$

É curioso perceber que, no âmbito das teses analisadas, a temática do bairro como referência não tenha advindo da ideia de tomá-lo previamente como campo exclusivo da pesquisa. A tese já referida, cujo tema enfocou as disputas entre duas torcidas organizadas de um mesmo time de futebol, no decorrer da pesquisa incorporou o bairro como espaço de referência (Ribeiro, 2010). A autora encontrou esse recorte "nativo" de maneira marcante na sua pesquisa etnográfica a partir de análise dos conflitos entre as torcidas no estádio. A partir de certo momento da pesquisa, ao centrar suas observações nas entrevistas, percebeu que o bairro Barroso II abrigava uma das gangues mais atuantes e "perigosas" ligadas às torcidas organizadas, ${ }^{17}$ fato que autorizava a incorporação desse lugar como portador de uma rivalidade muitas vezes superior à do próprio time.

Em artigo em que analisa a produção recente no campo da sociologia urbana, Barreira (2007) também vê o bairro como campo de pesquisa que oferece amplas possibilidades ao olhar. A autora propõe mesmo uma "sociologia dos bairros", que poderia se constituir em um campo de investigação e análise:

Não obstante a vigência de processos globais, atuando como pano de fundo no âmbito dos registros sociológicos da cidade, torna-se importante retomar o contexto das práticas cotidianas reveladoras de sentidos e processos citadinos. Trata-se de pensar as dinâmicas estruturais mais

${ }^{16}$ Entrevista concedida à Geísa Mattos em outubro de 2012, durante a Anpocs, em Águas de Lindóia (SP), anteriormente mencionada.

17 "Este bairro, melhor dizendo, o grupo composto por jovens moradores de lá é considerado, dentro da torcida, sob o peso de forte estigma pessoal, social e espacial. Eles são definidos pela geopolítica urbana juvenil como os que não estão nem aí, os que não têm nada a perder, os perigosos, os que brigam e roubam, aqueles com quem o diálogo é quase impossível. Justamente por isso me interessei por este bairro em particular“" (Ribeiro, 2010, p. 120). 
abrangentes mediante o que poderia ser designado de "sociologia dos bairros", entendendo que, a partir de espaços microssociais, é possível examinar perspectivas globais da cidade. O bairro, como lugar expressivo de práticas sociais, permite ultrapassar a lógica linear de certas generalizações, atentando para situações mais densas e contraditórias vivenciadas no cotidiano da cidade (Barreira, 2007, p. 165-166).

No mesmo artigo, a autora também lembra que os bairros já foram objetos frequentes de pesquisa no Brasil dos anos 1980 e 1990, atentando, porém, para o fato de que, nesse período, eles eram interpretados como espaços privilegiados das lutas sociais que se deslocavam das fábricas e locais de trabalho para os lugares de moradia. Lá se desenvolviam os "movimentos sociais" por meio dos quais os moradores ou "líderes comunitários" dirigiam suas reivindicações ao Estado (Barreira, 1995; Scherer-Warren, 1999; Gohn, 2003).

Se esses trabalhos tiveram como referência a ideia de bairro como uma totalidade, ao pensá-lo de modo fundamentalmente "político", atualmente, as perspectivas dos trabalhos sobre bairros nem sempre têm o Estado como referência, embora também incorporem categorias sociais articuladas às relações de poder segundo a influência de vários autores.

As teses e dissertações que tomaram os contextos de moradia como bases de suas reflexões favorecem a percepção da complexidade das diferentes ordens espaciais, pelas quais os sujeitos geram seus territórios em um mesmo lugar, identificado como "bairro" nos mapas oficiais.

Vários dos trabalhos que foram objeto de análise na pesquisa identificam a existência de “centros" e "periferias" no interior desses bairros, sendo eles próprios percebidos como periféricos em relação ao centro oficial. "De perto e dentro" para usar uma expressão de Magnani (2002), ${ }^{18}$ muito citada na maioria destes trabalhos -, considerando o fato de que um bairro pode ser visto como "perigoso" em sua totalidade, sobretudo pela

${ }^{18}$ Magnani (2002) é referência em grande parte dos trabalhos aqui citados, ao propor uma antropologia da cidade voltada para uma compreensão mais calcada na identificação, descrição e reflexão sobre situações e sujeitos em seus usos cotidianos do espaço urbano, que não perca de vista essas referências em nome de questões políticas ou mesmo de poéticas sedutoras. mídia, seus moradores diferenciam, relativizam e hierarquizam internamente o espaço em que habitam, percebendo quais são os territórios do "perigo" a partir do lugar social em que se encontram. Significativo, nesse sentido, é a pesquisa que toma como objeto a Praça da Aerolândia, que se tornou alvo de conflitos pelo fato de ser utilizada por jovens usuários de drogas (Matos Jr., 2008). Ao escolher a perspectiva dos usuários, o autor encontra também os seus medos e percepções feitas com base na identificação de "perigos" normalmente atribuídos aos outros. Outra praça também alvo de conflitos, que foi objeto de pesquisa, é a da Gentilândia, situada próxima ao centro da cidade, que, sendo frequentada por jovens homossexuais entre os anos 2004 e 2008, gerou fortes reações homofóbicas por parte de comerciantes e moradores do entorno. A pesquisa que deu origem à dissertação mostrou como a expressão pública da sexualidade associava-se a conflitos em torno do uso de um espaço urbano (Viana, 2009).

A percepção da segmentação dos espaços e suas divisões simbólicas incidem sobre diferentes percepções de "nós” e dos “outros”, que são categorias de que os moradores da cidade se utilizam para diferenciar os bairros entre si, ou as divisões internas dentro de um mesmo território. ${ }^{19} \mathrm{Em}$ outras situações, as designações de "favela", "bairro", "comunidade” tornam-se uma via muito profícua para se analisar tanto a percepção dos sujeitos moradores sobre suas práticas como a relação que estabelecem com os espaços urbanos (Matos, 2004; Sá, 2010).

As categorizações espaciais não são, entretanto, fixas. Mesmo entre os trabalhos que tomam "o centro da cidade" como objeto (Barbosa, 1997; Pimentel, 1998; Vasconcelos, 2008), são encontradas problematizações acerca da própria ideia de centro, pelo menos nas pesquisas mais recentes, considerando-se as mudanças de ordem econômica política e simbólica que caracterizam aquela área da

${ }^{19}$ Muito influentes para esses tipos de interpretação de "centro" e "periferia" dentro desses trabalhos que tomam os bairros como referência são as leituras de Norbert Elias e James Scotson, em Os Estabelecidos e os Outsiders (2000), e Loïc Wacquant, em Os Condenados da Cidade (2001). 
cidade a partir da segunda metade do século XX.

As propostas chamadas de "requalificação" observadas em determinados lugares da cidade, como o centro e a Praia de Iracema (bairro que foi “campo" de cinco dos 27 trabalhos aqui analisados), também são discutidas à luz da ideia de memória e patrimônio como construções sociais.

Em pesquisa sobre a Praia de Iracema, uma das dissertações analisadas refletiu sobre como se constrói uma "memória" que subsidia, de forma hegemônica, uma versão do passado (Schramm, 2001). A análise das intervenções do Poder Público no bairro demonstrou que o projeto de requalificação da Praia de Iracema,

[...] para abrigar essas novas funções, em meados da década de 1900, apoiou-se nas memórias de determinados grupos sociais, referendando-as como sendo a 'tradição' da Praia de Iracema, em detrimento das memórias de outros grupos, que foram sendo apagadas ou obscurecidas (p. 2).

Em perspectiva analítica mais voltada para o conflito entre frequentadores da Praia de Iracema, uma tese analisou os diferentes usos do espaço com suas tensões e apropriações marcadas por recortes culturais e políticos que se definem por temporalidades (Bezerra, 2008). Os sentidos negativos de "decadência" e positivos de "boemia" confrontam-se em vários discursos sobre o bairro, interferindo na construção da ideia de patrimônio.

Tomar o bairro como referência, assim como a cidade, não teve como consequência substancializálos. A perspectiva microssociológica permitiu compreender a complexidade das ordens territoriais e subjetivas que se entrelaçavam dentro de cada espaço delimitado oficialmente como "bairro". Os mapas, ao serem superpostos, mostraram-se bastante heterogêneos. É essa heterogeneidade e complexidade que o conjunto das pesquisas aqui analisadas contribui para revelar. É notório ressaltar que as pesquisas são construídas tendo em vista a especificidade e a variação entre os bairros. Estudar o patrimônio, a violência ou as práticas de lazer e contestação revela também o lugar dos bairros como objeto de um olhar acadêmico.

\section{A CIDADE COMO PANO DE FUNDO}

Os trabalhos analisados trouxeram à tona o antigo tema sociológico da totalidade, mostrando a eficácia de uma microssociologia que não deve abdicar da ideia de inserir os objetos de pesquisa na trama dos processos sociais. Se o bairro é um microcosmo de um universo relacional mais complexo, o esforço de uma recomposição de idas e vindas deve ser apreciado tendo em vista evitar a percepção de uma particularização de práticas sociais cujo sentido se efetiva no contexto urbano mais amplo, envolvendo a cidade, sua história e suas conexões com processos mais abrangentes de expressão da vida social. Assim, como separar os conflitos em torno de estigmas sobre a sexualidade das práticas afirmativas de gênero e as reações consequentes que se efetivam na Praça da Gentilândia, mas se apresentam também em outros lugares e contextos urbanos? Como não associar as disputas de hegemonia sobre o patrimônio a políticas de gestão da cidade que radicalizam usos e disciplinas na tensão permanente de espaços que se efetiva na cidade? Essas e outras questões levam a pensar o bairro em sua face dupla, que tende a separar-se do conjunto na perspectiva de afirmação de identidades geográficas, ao mesmo tempo em que nele se associam, cotidianamente, as práticas e propostas de intervenção que permeiam a vida urbana em seus aspectos sociais, econômicos e simbólicos.

É também relevante ressaltar que o olhar sobre espaços microssociais passa a ter sentido no momento em que uma metrópole como Fortaleza, aproximadamente com dois e meio milhões de habitantes, quinta capital brasileira em termos populacionais, passa a abrigar complexidades, diversificando áreas de vida e consumo urbano e constituindo espaços de expressividade múltipla. Uma espacialidade descentralizada e atravessada por diversidades contribui objetivamente para que a incidência de olhares sociológicos e (ou) antropológicos adquira um teor fecundo, sobretudo se forem consideradas as articulações entre aspectos micro e macrossociais. 
Comparando-se os trabalhos sobre movimentos sociais da década de 1980 com as teses e dissertações mais recentes, é possível observar algumas diferenças. Aqueles que se aproximaram de uma linha antropológica ou sociológica, voltada para identificar o exercício da política no cotidiano, guardaram o patrimônio de abordagens centradas em desigualdades de acesso aos bens culturais e políticos, pondo-se, muitas vezes, como contribuição ao desvendamento processual de dinâmicas mais amplas que permeavam a exclusão de atores no cenário social e político. As novas abordagens, apostando em microrrelações sem a correspondência de atores coletivos, distanciaramse, de algum modo, da ideia de cidade como um modelo provisório de totalidade. Se o conceito de território permitiu o exame de sociabilidades emergentes, usos e contravenções variadas, foi ele também indutor de uma cidade multifacetada. Isso quer dizer que o registro de diversidades, dinâmicas cotidianas e expressões simbólicas e territoriais sinalizou descobertas, acionando, no entanto, a necessidade de uma recomposição da universalidade urbana com interseções a serem buscadas.

É relevante também entender o que poderia ser denominado de passagem das abordagens estruturais para as microssociológicas como uma espécie de movimento de paradigmas capazes de encontrar, em situações mais delimitadas, a possibilidade de registro de uma rede mais complexa de interações. A “descoberta” de atores concretos, na sua diversidade de ações, e a diferenciação dos significados dos coletivos apontou, por exemplo, a metrópole "com a cadeira na calçada", a sociabilidade da vizinhança convivendo com o anonimato e a atitude de indiferença (Simmel, 1979).

Essa aproximação da lupa, que as teses e dissertações editam, tal qual um zoom da tela eletrônica, sinalizou o cotidiano na sua maré de interseções, fazendo emergir a profusão de ações e categorias sociais normalmente escondidas em uma abordagem exclusivamente estrutural. O bairro $d a$ cidade, o bairro na cidade e o bairro como cidade são, portanto, recomposições importantes que esse conjunto de teses e dissertações apontou, servin- do de referência para análise dessa produção em outros contextos acadêmicos.

Recebido para publicação em 22 de fevereiro de 2012 Aceito em 12 de julho de 2013

\section{REFERÊNCIAS}

ALBUQUERQUE, Cynthia. Nas ondas do surfe: estilos de vida, territorialização e experimentação juvenil no espaço urbano. 2007. Dissertação (Mestrado) - Programa de PósGraduação em Sociologia (PPGS), Universidade Federal do Ceará. Fortaleza, 2007.

ANDRADE, Fátima. A política social e o Estado: uma abordagem sociológica dos programas públicos de assistência social no Ceará. 1991 Dissertação (Mestrado) - Programa de Pós-Graduação em Sociologia (PPGS), Universidade Federal do Ceará. Fortaleza, 1991. ARAGÃO, Liduína. As trilhas da cidade pelas memórias
dos trabalhadores do lixo em Fortaleza. 2002. Dissertação (Mestrado) - Programa de Pós-Graduação em Sociologia (PPGS), Universidade Federal do Ceará. Fortaleza, 2002.

AUGÉ, Marc. Não-lugares: introdução a uma antropologia da supermodernidade. Campinas: Papirus, 1994.

BAILEY, F.G. Gifs and poison: the politics of reputation. Oxford: Basil Blackwell, 1971.

BARBOSA, Francisco Carlos. A força do hábito: condutas transgressoras na Fortaleza remodelada. Dissertação (Mestrado) - Programa de Pós-Graduação em Sociologiada (PPGS), Universidade Federal do Ceará, 1997.

BARBOZA FILHO, Rubem; PERLATTO, Fernando (Org.) Uma sociologia indignada. Diálogos com Luiz Werneck Vianna. Juiz de Fora, MG: Ed. UFJF, 2012.

BARREIRA, Irlys. Introdução. In: PROGRAMA DE PÓSGRADUAÇÃO EM SOCIOLLOGIA (PPGS). Catálogo de Dissertações. (1978/1995). Fortaleza: Universidade Federal do Ceará. 1995.

Frutos do tempo: Movimentos Sociais Ontem e Hoje. In: Reis Elisa Tavares Maria Herminia Fry Peter. (Org.). Pluralismo Espaço Social e Pesquisa. São Paulo: Hucitec/Anpocs, 1995, p. 58-77.

A cultura e a política: encontros frutíferos de uma agenda de pesquisa. Revista de Ciências Sociais UFC, v. 28, n.1/2, Fortaleza, 1997, p. 34-48.

Usos da cidade: conflitos em torno da memória e imagem de um bairro. Análise Social, Lisboa, ICS, v.42, n.182, p.163-180, 2007.

BEZERRA, Roselane. O bairro Praia de Iracema entre o "adeus" e a "boemia". 2008. Tese Tese (Doutorado em Sociologia) - Programa de Pós-Graduação em Sociologiada (PPGS), Universidade Federal do Ceará. Fortaleza, 2008.

CASTELLS, Manuel. Cidade, democracia e socialismo. Rio de Janeiro: Paz e Terra, 1980.

CERTEAU, Michel. A invenção do cotidiano: artes de fazer. Petrópolis: Vozes, 1998.

CORDEIRO, Celeste. CEBs: uma nova socialidade? 1989. Dissertação (Mestrado) - Programa de Pós-Graduação em Sociologia (PPGS), Universidade Federal do Ceará. Fortaleza, 1989. 
DELEUZE, Gilles; GUATTARI, Felix. Mil platôs: capitalismo e esquizofrenia. São Paulo: Ed. 34, 1995. v.1.

DIÓGENES, Glória. Cartografias da cultura e da violência. São Paulo: Annalume; PPGS/UFC, 1998.

ECKERT Cornélia. Cidade e política: nas trilhas de uma antropologia da e na cidade no Brasil. In: MARTINS, Carlos Benedito (Coord.) Antropologia. São Paulo: Horizontes das Ciências Sociais no Brasil; Anpocs, 2010.

FOUCAULT, Michel. Microfísica do poder. Rio de Janeiro: Ed. Graal, 1979.

FREHSE, Fraya; LEITE, Rogério Proença. Espaço Urbano no Brasil. Sociologia, São Paulo, Horizontes das Ciências Sociais no Brasil; Anpocs, 2010.

FRUGÓLI JR., Heitor. O urbano em questão na antropologia: interfaces com a sociologia. Revista de Antropologia, São Paulo, USP, v.48, n.1, 2005.

GEERTZ, Clifford. A interpretação das culturas. Rio de Janeiro: LCT Editora, 1989.

GOHN, Maria da Glória (Org.) Movimentos sociais no início do século XXI. Petrópolis: Vozes, 2003.

GOLDMAN, Marcio; PALMEIRA, Moacir. Apresentação. In: ; $\quad$ (Org.) Antropologia, voto e representaçẫo política. Rio de Janeiro: Contra Capa Livraria, 1996 GOMES, Paulo César. A condição urbana: ensaios de geopolítica da cidade. Rio de Janeiro: Bertrand Brasil, 2002.

GUATTARI, F. Espaço e poder: a criação de territórios na cidade. Espaço \& Debates: revista de Estudos Regionais e Urbanos, São Paulo, v.5, n.16, 1985.

; ROLNIK, S. Micropolítica: cartografia do desejo. Petrópolis: Vozes, 1986.

HAESBAERT, Rogério; LIMONARD, Ester. O território em tempos de globalização. ETC, Espaço, Tempo e Crítica, São Paulo, v.1, n. 2, p.39-52, 2007.

HANNERZ, Ulf. Explorer la ville. Paris: Les Editions Du Minuit, 1983.

KOWARICK, Lúcio. A espoliação urbana. 2.ed. São Paulo: Paz e Terra, 1983.

MAGNANI, José Guilherme. De perto e de dentro: notas para uma etnografia urbana. Revista Brasileira de Ciências Sociais, São Paulo,v.17, n.49, jun. 2002.

Quando o campo é a cidade. Fazendo antropologia na metrópole. Na Metrópole: textos de antropologia urbana. São Paulo: Edusp, 2000.
1985. Dissertação (Mestrado) - Programa de Pós-Graduação em Sociologia (PPGS), Universidade Federal do Ceará. Fortaleza, 1985.

MONTEIRO JR. Fortaleza na ponta do anzol. 2009. Dissertação (Mestrado) - Programa de Pós-Graduação em Sociologia (PPGS), Universidade Federal do Ceará. Fortaleza, 2009.

NUNES, Márcia. Imprensa e poder: o jornal O Povo durante os dois governos de Virgílio Távora (1963-1966; 1979-1982). 1991. Dissertação (Mestrado) - Programa de Pós-Graduação em Sociologia (PPGS), Universidade Federal do Ceará. Fortaleza, 1991.

OLIVEIRA, Catarina. O direito à palavra: comunicação, cultura e mediações - a experiência das rádios comunitárias em Fortaleza. 1994. Dissertação (Mestrado) - Programa de Pós-Graduação em Sociologia (PPGS), Universidade Federal do Ceará. Fortaleza, 1994.

PAIVA, Luiz Fábio. Contingências da violência em um território estigmatizado. 2007. Dissertação (Mestrado) Programa de Pós-Graduação em Sociologia (PPGS) Universidade Federal do Ceará. Fortaleza, 2007.

PERLONGUER, N. Territórios marginais. In: MAGALHÃES, Maria (Org.) Na sombra da cidade. São Paulo: Editora Escuta, 1995.

PIMENTEL, Lídia. Praça José de Alencar: pedaços da cidade, cenário da vida. 1998. Dissertação (Mestrado) - Programa de Pós-Graduação em Sociologia (PPGS), Universidade Federal do Ceará. Fortaleza, 1998.

PRADO, Antonia Ieda. Uma rua, um bairro, uma cidade. 2003. Dissertação (Mestrado) - Programa de Pós-Graduação em Sociologia (PPGS), Universidade Federal do Ceará Fortaleza, 2003.

PRÉTECEILLE, Edmond. Crise urbaine, fragmentación sociale et descentralization. Paris: CNRS, 1985.

RIBEIRO, Josiane. Conflitos, territórios e identificações: o encontro de experiências nas torcidas organizadas Cearamor e M.O.F.I. 2010. Tese (Doutorado em Sociologia) - Programa de Pós-Graduação em Sociologia (PPGS), Universidade Federal do Ceará. Fortaleza, 2010.

SÁ, Leonardo. Guerra, mundão e consideração: uma etnografia das relações sociais dos jovens no Serviluz. 2010. Tese (Doutorado em Sociologia) - Programa de PósGraduação em Sociologia (PPGS), Universidade Federal do Ceará. Fortaleza, 2010.

SCHERER-WARREN, Ilse. Cidadania sem fronteiras: ações coletivas na era da globalização. São Paulo: Hucitec, 1999.

SCHRAMM, Solange. Território Livre de Iracema: só o nome ficou? 2001. Dissertação (Mestrado) - Programa de Pós-Graduação em Sociologia (PPGS), Universidade Federal do Ceará. Fortaleza, 2001.

SIMMEL, G. A Metrópole e a vida mental. In: VELHO, Otavio (Org.) O fenômeno urbano. Rio de Janeiro: Biblioteca de Ciências Sociais, 1979.

SOUSA, Maria Meirice. Gerentes e/ou representantes: líderes populares e programas sociais nos bairros de Fortaleza. Dissertação (Mestrado) - Programa de Pós-Graduação em Sociologia (PPGS), Universidade Federal do Ceará. Fortaleza, 1997

SOUZA, Marcelo José Lopes. O território: sobre espaço e poder, autonomia e desenvolvimento. In: CASTRO, Inaiá; GOMES, Paulo; CORREAA, Roberto (Org.). Geografia: conceitos e temas. 2.ed. Rio de Janeiro: Bertrand Brasil, 2000.

TOPALOV, Cristian. La urbanization capitalista. México: Editorial Edicol, 1979.

VALE, Alexandre. Cenas de um público implícito: territorialidade marginal, pornografia e prostituição travesti no cine Jangada. 1997. Dissertação (Mestrado) - 
Programa de Pós-Graduação em Sociologia (PPGS), Universidade Federal do Ceará. Fortaleza, 1997.

No escurinho do cinema: cenas de um público implícito. São Paulo: Annablume; Fortaleza: Secretaria da Cultura e Desporto do Estado do Ceará, 2000.

VASCONCELOS, Leonardo C. Um centro para uma cidade (Pós-)Moderna: a requalificação do centro histórico de Fortaleza. 2008. Dissertação ( Mestrado) - Programa de Pós-Graduação em Sociologia (PPGS), Universidade Federal do Ceará. Fortaleza, 2008.

VIANA, Waldiane. Manifestações homofóbicas em espaços públicos: Praça da Gentilândia em Fortaleza. Disserta- ção (Mestrado) - Programa de Pós-Graduação em Sociologia (PPGS), Universidade Federal do Ceará. Fortaleza, 2009

VIEIRA, Sulamita (Org.). Caminhos das Ciências Sociais? Catálogo de dissertações e teses (1978-2002). Fortaleza: PPGS/UFC, 2002.

WACQUANT, Loïc. Os condenados da cidade. Rio de Janeiro: Revan/FASE, 2001.

WIRTH, Louis. O urbanismo como modo de vida. In: VELHO, Gilberto. O fenômeno urbano. Rio de Janeiro: Ed. Guanabara, 1987. 


\section{SUBVERTING THE LOOK: temporal evidence of a micro-sociology of urban spaces}

\author{
Irlys Alencar Firmo Barreira \\ Geísa Mattos de Araújo Lima
}

This article, with its basis in theses and dissertations produced in the second half of the 1990's, in the Post-graduate Program in Sociology at the Federal University of Ceará, analyzes the theoretico-empirical trajectory of sociological and anthropological production that had the theme of the city as its object of investigation. The works analyzed express theoretical and methodological movements predominant in the social sciences, during this time in Brazil. They also demonstrate the growing interest in a micro-sociological scale in approaches to the urban, as one of the effects of the influence of anthropology in the methodological and theoretical treatment of these objects. There emerges, from this set of works, an element of conflict in the practices of power, in relation to territories in cities, influenced by approaches coming from political geography. French sociology and history contribute with theoretical perspectives that prioritize the sense of creation and insubordination conferred on spaces as lived by distinct social actors. In this set of works, the neighborhood appears as a microcosm of social practices permeated by senses of belonging and conflict with place, as expressive of broader social struggles.

KEY-WORDS: Sociology, Urban Spaces, Approaches. Student production.

\section{SUBVERSIONSDUREGARD:évidencestemporelles d'une microsociologie des espaces urbains}

\author{
Irlys Alencar Firmo Barreira \\ Geísa Mattos de Araújo Lima
}

Ce travail, basé sur des thèses et des mémoires produits dans la deuxième moitié des années 1990 au sein du Programme d'Etudes de $3^{\text {e }}$ Cycle en Sociologie de l'Université Fédérale du Ceara, analyse le parcours théorique et empirique de la production sociologique et anthropologique ayant comme thème de recherche la ville. Les recherches analysées sont témoins des mouvements théoriques et méthodologiques dominant à cette époque dans les Sciences Sociales au Brésil. Elles démontrent aussi un intérêt croissant pour des découpages micro sociologiques dans les approches concernant les thèmes urbains, reflet de l'influence de l'anthropologie dans le traitement théorique et méthodologique des objets. Il ressort de l'ensemble de ces travaux une dimension conflictuelle des pratiques du pouvoir concernant les territoires de la ville, travaux influencés par des approches dues à une géographie politique. La sociologie et l'historiographie françaises apportent leur contribution dans une perspective théorique qui met l'accent sur les sens de création et d'insubordination attribués aux lieux où ont vécu divers acteurs sociaux. Dans l'ensemble des travaux, le quartier apparaît comme un microcosme de pratiques sociales imprégnées par des sentiments d'appartenance et par des conflits de lieux qui sont le reflet de plus amples luttes sociales.

Mots-CLÉs: Sociologie. Espaces urbains. Approches. Production d'étudiants.

Irlys Alencar Firmo Barreira - Doutora em Sociologia. Professora titular de sociologia do Programa de Pósgraduação em Sociologia da Universidade Federal do Ceará. Pós doutora na École des Hautes Études en Sciences Sociales - EHESS (Paris) e Instituto de Ciências Sociais - ICS (Lisboa). Pesquisadora do CNPq. Coordena o laboratório de pesquisa em cultura e política - LEPEC. Tem como campo de investigação experiência nas áreas de Sociologia, com interfaces nas áreas de antropologia e política, atuando principalmente nos seguintes temas: cidade, política, cultura, gênero e movimentos sociais. Publicações recentes: O trabalho intelectual sob a óptica do artesanato e a cidade como campo de pesquisa. Revista Brasileira de Sociologia/ Sociedade Brasileira de Sociologia SBS, v. 01, p. 275-296, 2013; Campos de ajuda e modos de pertencimento: um mapa moral da representação política em campanha eleitoral. Horizontes Antropológicos (UFRGS. Impresso), v. 37, p. 307-335, 2012; Social Movements, Culture and Politcs in the Work of Brazilian Sociologists. Latin American Perspectives, v. 20, p. 23-42, 2011.

Geísa Mattos de Araújo Lima - Doutora em Sociologia. Professora do Departamento de Ciências Sociais e do Programa de Pós-Graduação em Sociologia da Universidade Federal do Ceará - UFC. Integra a equipe de pesquisadores do Laboratório de Pesquisas em Política e Cultura - LEPEC. Desenvolve pesquisas em Sociologia e Antropologia, atuando nos seguintes temas: campanha eleitoral, lideranças comunitárias, espaço urbano, comunidade e política, sociologia da comunicação. Publicações recentes: $O$ “artista invasor" e os códigos do jornalismo cultural. Revista FAMECOS (Online), v. 18, p. 408-430, 2011; Tática, trapaças e Astúcias: A Política da Vida Real. Revista de Ciências Sociais (Fortaleza), Fortaleza, v. 33, p. 46-50, 2002; A Favor da Comunidade. Modos de viver a política no bairro. 1 $^{\mathrm{a}}$. ed. Campinas: Pontes, 2012. v. 500. 272p.; Nordeste, memórias e narrativas da mídia. 1. ed. Fortaleza: Instituto de Referência da Imagem e do Som (IRIS) e Expressão Gráfica Editora, 2010. v. 1000. 271p 